\title{
Study of morphological structures of historical centres as a basic tool for understanding the new conditions of social habitat. Quito, Suzhou, and Syracuse
}

\section{Andrea Gritti', Verónica Rosero², Juan Carlos Dall'Asta ${ }^{3}$, Daniele Rocchio4, Riccardo Porreca ${ }^{4}$, Franco Tagliabue ${ }^{1}$}

${ }^{1}$ Architectural and Urban Design School, Politecnico di Milano. Milano, Italy

${ }^{2}$ Faculty of Architecture: Universidad Internacional SEK and Universidad Central del Ecuador. Quito, Ecuador

${ }^{3}$ Dep. of Architecture, Xi'an Jiaotong Liverpool University, Suzhou, China ${ }^{4}$ Faculty of Architecture, Universidad Tecnológica Equinoccial. Quito, Ecuador E-mail: vero.rosero.a@gmail.com; andrea.gritti@polimi.it; juancarlos.dallasta@xjtlu.edu.cn; daniele.rocchio@ute.edu.ec; riccardo.porreca@gmail.com; ifdesign@tiscali.it

\begin{abstract}
In the age of globalization, architecture (through an identity crisis) is directly connected with the loss of progressive recognition of morphological studies of city and territory, in a gradual replacement with real-time views of phenomena and urban facts. The satellite gaze finally flattens the interpretation ability of living spaces that were the prerogative of the morphological studies. The actual complexity of cities and territories escapes from the architect's eyes as they increase their technical capability to know details. The season of great renovations and methodological studies that had powered the 1960s, $70 \mathrm{~s}$ and $80 \mathrm{~s}$ seems hopelessly distant. Studies on social, economic, and environmental components of the cities and territories (infrastructure, public space, environmental networks) are so proliferated without actually being supported by adequate interpretations of their physical-spatial dynamics. The result: a substantial failure of architectural design to express human habitat visions. It is imperative a theoretical and practical effort to pick up the threads of an interrupted conversation, and return where these studies have expressed their richest potential: the historical centers, the places with most dense and rich heritage. Historical centers of cities like Quito, Syracuse and Suzhou have settled and stratified the morphological structures of several different settlement patterns. As a result, architecture has demonstrated an ability of description and interpretation. Reflecting on how this goal was reached in these cities (by means much less powerful than the current) settlement will be able to bid the morphological component of urban and regional studies and architecture project as a fundamental tool for understanding the human habitat.
\end{abstract}

Keywords: Historical centers, habitat, public space, architecture, heritage

\section{Introduction. Three listed cities}

There is no doubt that in the globalization age new ways of defining the "meaning of the city" are being experienced. They are different from other morphological studies that were practiced in the period of their greatest development (Aymonino, 2000). At the heart of this new condition is the issue of "recognition" of exceptional values (Unesco Report, 2016), no longer referring to the local specificity of individual contexts, but extended to a planetary 
scale. In this changed perspective, a decisive role is certainly played by the choices of UNESCO sites on the World Heritage List, and in particular by the complex procedures accompanying the entry and maintenance of the sites in this exclusive list (Unesco Report , 2016)

Leaving aside the crucial issue posed by the "dizziness of the list" and its paradoxes, which will be time to come back (Eco, 2010), the theme taken in the title from the morphological exploration of three urban realities can be researched. The three cities are included in the UNESCO list in three different moments and on three different continents: the historic center of Quito in Latin America (1978), the classic gardens of Suzhou (1997-2000) In Jiangsu province in the east of China, the city of Syracuse and the Necropolis of Pantalica in the heart of the Euro-Mediterranean basin (2005). Methodology. Places of memory, voids and territories

If we observe these three cases with essentially dynamic instruments of morphological and urban studies, the evidence that emerges, clearly shows the substantial staticity of the criteria with which they were included in the UNESCO list. In Quito, Suzhou and Syracuse/Pantalica, the dialectic between the dynamics of urban and static forms of capital appreciation criteria is responsible for the communities that inhabit these same places and the way they experience in their daily lives their exceptional diversity ("Heritage" entries by P. Ciorra and C. Younes in Recycled theories, 2016).

To prevent these consequences from being the basis of the process set up by UNESCO and ICOMOS, delivering in future items of heritage without established humanity or stubbornly hostile communities to the inclusion of their election sites in the list certifying their universal value, it is necessary to re-allocate urban studies to a fundamental role in the process of recognizing the physical-environmental and historical-cultural meaning of cities. In this perspective, the most striking cases are only the pretext for extending this method of investigation of identities and differences (D'Alfonso, 1995) to all components of human settlements, knowing that at least two symmetrical paradoxes lie on the dizzying list UNESCO promoted: on the one hand, the risk that it runs out of prematurely, and on the other, the risk that it never ends, potentially including every fragment of the anthropic landscape in an indefinite perspective.

Of these two paradoxes, the first describes a regression of universal culture that can only be anticipated by the expression of dystopia (by J. Swift, Gulliver's travels, published in 1726, to G. Orwell, 1984, published in 1948), the latter, instead, looks to its announced of the affirmation of an allegorical dimension of heritage (Choay, 1992) potentially capable of impregnating everywhere on the planet, with the same uncontrollable effects Jorge Luis Borges attributed to the application of Royce's map (Borges, Del rigor of the ciencia, 1946).

In an era when mapping of terrestrial space through satellite view is revealing the superficial consistency of every corner of the planet (J. Brottom, The History of the World in 12 Maps, 2016), confining in a corner the specific demonstrative capabilities of urban morphological studies (P. Virilio, L'espace critique, 1984), this second paradox appears to be the most insidious.

For this reason, the proposed methodology assumes a specific point of view, used as a probe to detect the complexity of the cases analyzed and to open to their reinterpretation in design terms. Thus, for the analysis of the historical centre of Quito, it is proposed to analyze the urban public space from the definition of "places of memory" as a system of itineraries, crossings and monuments (Augé, 2009).

Similarly to the analysis of the classic gardens of Suzhou, it is proposed an insight to a place of memory formed by the dynamic transformation through space and time of the life in the void, where emptiness and absence (considering this concepts dense and complex) can be expressed spatially. It has been assessed through the lens of the concept that "sense" of a place can be preserved despite its changes and transformations. (Ricci, 2000).

Finally, to investigate the city of Syracuse and the Necropolis of Pantalica, the relationship between the archaeological density of urban space and the rarefied composition of the vagues terrains, recurrent on the edge of the 
city, has been recalled, evoking the dialectics of two famous contributions by Saskia Sassen And Ignasi de Solà - Morales, devoted to the interpretation of the concept of "territory" (Solà Morales \& Sassen, 2003).

\section{Measurement and analysis}

The case of Quito. A dichotomy regarding the places of memory. If the construction of "places of memory"1 implies a long and slow process through time, it can be assumed that a historical centre is in its essence a place of memory. However, in the selection process of the ideal zone for being studied, exceptions were identified. For this city, there has been analysed three public spaces in the limit between the historical centre and the centre-north zone. These spaces (located in the transition to the modern zone) have particularities that singularize, through historic layers and contemporary interventions, the transition to another city model in time and space. The studied zone is characterised for being a "knot where the old city and modern city meet" (Peralta \& Moya, 2007) in which three public spaces are highlighted:

The first space is a strong preexistence of the colony: the Plaza San Blas (16th century), a symbol of the religious footprint imposed in the Spaniard colonization with one of the oldest churches of the city. In its origins, it sheltered indigenous meetings. From the 18th century, it has suffered several interventions. The most recent, attempt to integrate urbanly with a void (the second space of study) through the unification of the floor of both places with the same materials in a unique level.

The second space is a "square" as a result of a contemporary intervention (21st century), that started off with the demolition of a historical building: the National Library. It is a void that has intended to gain identity through an sculpture and a trendy green wall. Nevertheless, it is a kind of incidental space that lacks of defined authenticity, due to the demolition of a cultural and historical symbol, that was moreover, part of a logic of urban morphological structuring. The demolition propitiate the production of a banal space, far away from a dynamic transformation of the place in order to connect it with contemporary necessities; a non-place in terms of Augé. As Ignasi de solá Morales anticipated, it is not only the system of habitable spaces with its topographical, historical and social determination, it is fundamental a meeting place of formative activity, it means, to understand public spaces as places of interaction and stratification of the context.

The third space is La Alameda park, a historic milestone, witness of political and morphological transitions. The superposition of historical layers is appreciated through the Astronomic Observatory building (nineteenth century) located in its heart, or a series of iconic buildings of Quito's modernity (twentieth century) in its perimeter.

Since the heritage approach is more often associated with "doing" (practices or techniques such as restoring, rebuilding, revitalizing, etc. or management processes) than with "thinking" (critical discussion of the nature and symbol of heritage), observing these three spaces constitutes a tool for the analysis of contemporary places of memory, transcending from idealism to realism. Following the same sense of Augé's proposal, the chosen sites have been analyzed from three concepts: public space as itinerary, intersection, and monument. The urban space is individualized through an urbanistic approach on the one hand, and a perceptive approach on the other hand. Both components contribute to recognize its identity and synthesize categories of analysis. Thus, the urban space can be studied and classified according to geometric and anthropologic parameters that are translated into a line, an intersection of lines and a point of intersection. In the geographical scope, these three places are seen through three concepts: itinerary, crossing and monument. (Augé, 2009).

The urban space presupposes a community or groups of people who act in it. These actions generate flows of individuals moving inside it. In the historical centre of Quito many routes connect places of interest, such as Guayaquil street that connects the Sucre National Theater to the Quito Observatory in La Alameda park, or the Basilica of the National Vote that through 
the Francisco de Caldas street connects with Plaza San Blas. It is evident that there are "axes or paths that connect one place with another, which have been traced by men" (Augé, 2009). In the same portion of the city it is possible to identify points of convergence of paths or itineraries, it means, events along the way (Lynch, 1960) and where the possibility of occasional and voluntary human activities is greater (Gehl 1991, 2014). Plaza San Blas is the meeting point of the routes described above. However, there is another public space next to it, defined by the area of the demolished National Library, a space that was created ignoring the community practices; therefore, it suffers a lack of identity strength.

In fact, the presence of monumental architecture expresses the identity strength of urban space. The public places characterize these spaces by the memory of historical events and by their events during the year. Therefore, the temporal characterization, despite being discontinuous, gives these spaces a strong identity component that wants to be tangible expression of permanence or, at least, duration in time (Augé, 2009). Then the space of San Blas expresses a clear dichotomy between the generational continuity, determined by the presence of the itinerary, crossing, and monumental architecture (church of San Blas), and the contemporary urban void pending of a monumental event now absent (National Library).

With this background, it is necessary to consider the identity of Quito's heritage, specifically in the studied area, through the practice of "recognition" that can lead to an identification of the value not only patrimonial but human from the point of view of the social habitat. These are the criteria that led Quito to its declaration as a World Heritage Site2 in 19783:

ii): The influence of the Baroque school of Quito was recognized in the cultural domain, especially art - architecture, sculpture and painting - in all the cities of the Audiencia, and even in those of the neighbouring Audiencia. iv): Quito forms a harmonious sui generis where the actions of man and nature come together, to create a unique and transcendent work of its kind.
Thereby, it is an scenario where, in addition to the built value, Quito is emblematic of a marked interconnection between man and the natural and urban landscape, under temporal and spatial aspects. So the dichotomy of San Blas, demonstrates the necessity to valorize historical and social memory to strengthen the processes of identity in connection with contemporary needs. A true tradition is not a testimony of an outdated past, it is a living force that animates and informs the present. Far from implying the repetition of the past, tradition implies the reality of what lasts, a heritage that is received with the condition of making it fruitful, before transmitting it to the new generations. (Stravinsky, 2003).

\section{The case of the classical gardens in Suzhou. Manifest and partial synthesis of the space- time relationship in the East.}

The stratification as a superposition of the layers of urban memory, simultaneously shows the transformations of the settlement, it is the writing of its urban biography. They are layers of a dynamic system whose complexity must be investigated in the relationships between the different forms placed in time and space, paying attention to complex spatial connections capable of generating conditions of constant disorientation. The stratified topography interpreted as opening, flexibility and overlapping is increasingly interwoven, articulated and complex, produces interpretations capable of narrating the urban structure, its defects and potential, reveals the meaning of "place", places of "urban memory". Through layers it is possible to reconstruct a dynamic network of interconnections, a permanence system that narrates a plurality of events and urban memories, built with history and memory. The evolutionary and metamorphic stratification of the city protects the value of its urban memory and the link with the memory of the site. Soil is a substantial part of the architecture of a city, broad and varied "stratified matter" possessing "discontinuous continuity." In these transformations we read the passage of time and how to mark things: to understand the current reality, we also have to 

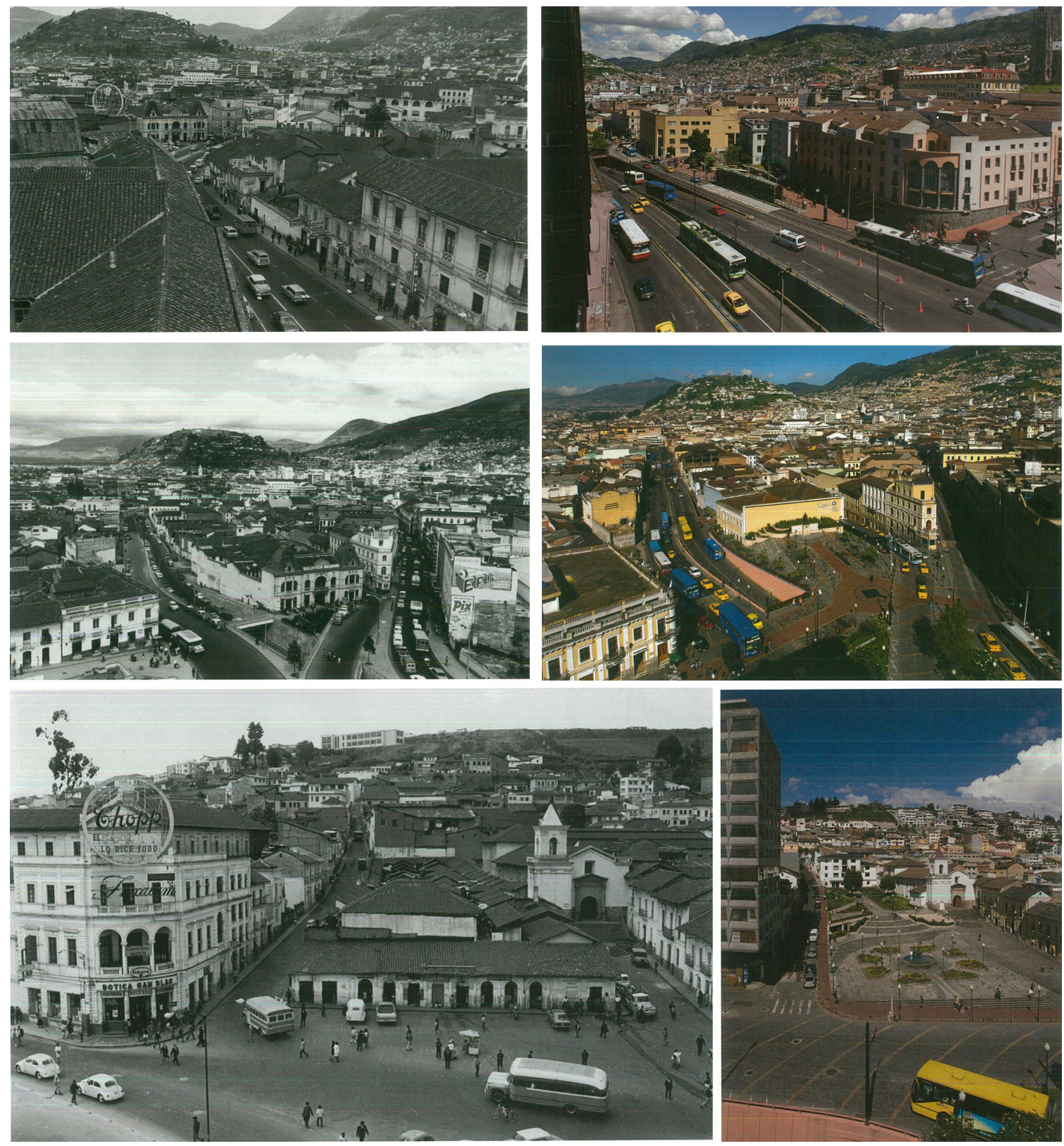

Figure 1. BEFORE AND AFTER. Morphological changes in the zone of study: 1960-2008. Source: Salvador, J. (2009). Historia de Quito "Luz de América". Fonsal.

understand the meaning of these mutations in terms of the project, so as to guide our future decisions consciously. The gardens of Suzhou are a privileged text of urban writing by layers, intangible memory of time and space. The urban morphology of Suzhou is constituted by a preexisting structure of elements of permanence that is well summarized once again in the concept of layers. The layers refer to the spatial transformation, the passage and the forms of connection in an extremely interesting physical-cultural context.

The interpretation of the Suzhou millenary organization by layers reveals a plurality of forces and assemblies, an overlap of layers that allows "to capture the connections that unite permanences and transformations..., the sense of novelty of many stays and continuity in apparent transformations: the preservation of the "sense" of a place despite its changes and transformations " (Ricci, 2000, p.145).

The nine gardens of Suzhou, humanity 

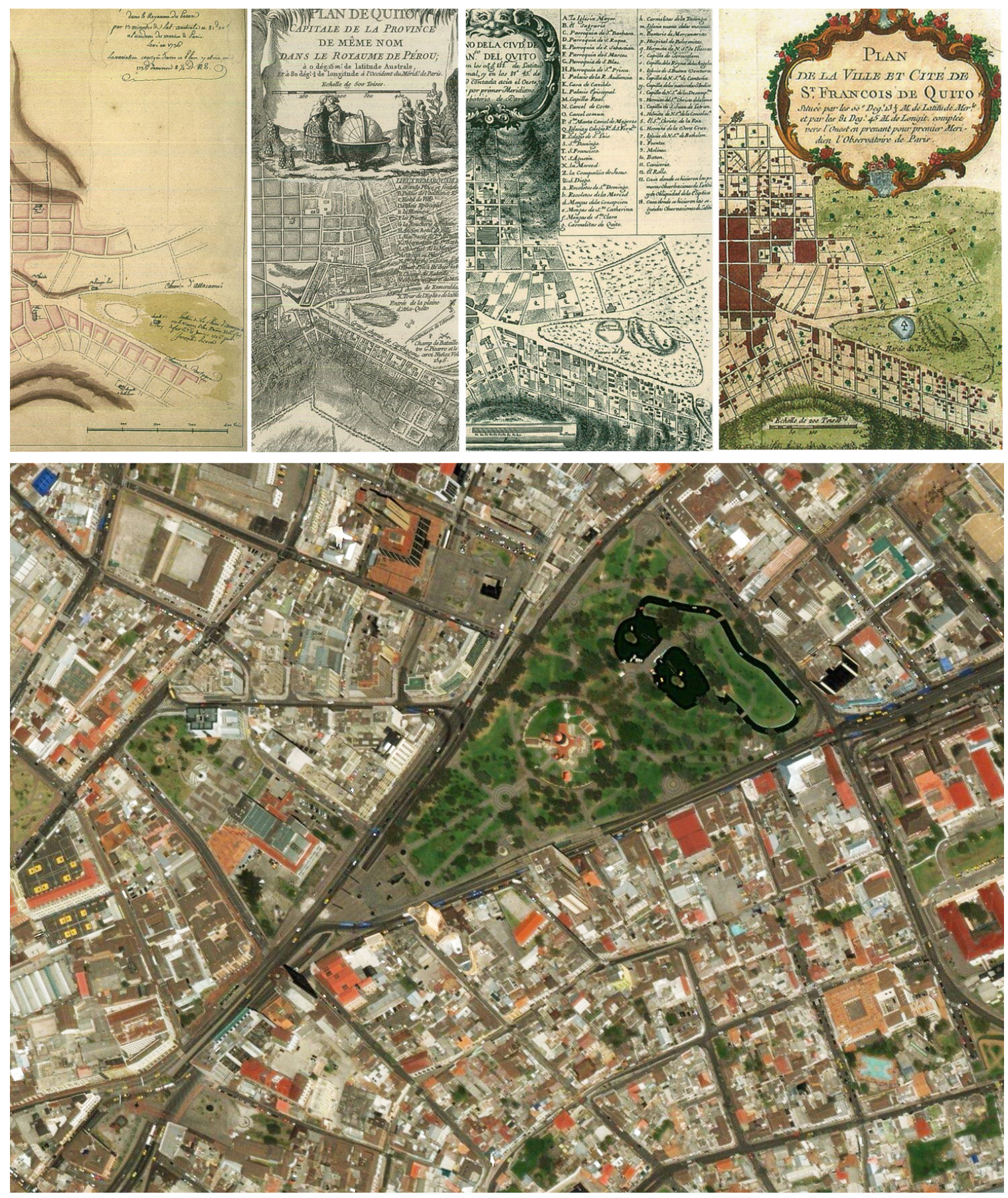

Figure 2. Up: Fragment of four maps of the study zone. 1751, 1736, s. XVIII y 1748. Source: Salvador, J. (2009). Historia de Quito “Luz de América". Fonsal. Pp. 138,139. Down: Current state of the zone. Source: Bing maps 2017

heritage protected by UNESCO, open an important reflection regarding to the meaning of urban memory. Of course, there is no doubt about the ability to delineate traits, signs, meanings in the ground to immediately become evident urban memory. But the theme and reflection that opens in front of the Suzhou gardens is apparently in complete contradiction with regard to the ability to witness the "material" memory. The gardens of UNESCO, as can be read in the official statement, are patrimony of humanity, substantially for its intangible value, linked not only to its extraordinary architecture, but especially to 
its meaning, as well as its weak and ephemeral content in continuous transformation. The Suzhou gardens reveal the value of time and empty space, open to new meanings of what is recognized as heritage.

The incredible experience in the gardens of Suzhou leads us to reflect deeply on the meaning of emptiness. In the specific case of Suzhou, the void is presented as a condition of possibilities, thus forms can be generated. Therefore, it is not background or scene, but space itself. To better explain this concept, we can think for example of the sukiya, in which the void becomes a present and active element, an agent of purification of the unnecessary, and a device that allows one to concentrate on the essential. The void transforms space: it has the power to reveal and improve the relationship between the elements of composition. Here the use of emptiness is neither contingent nor casual, but represents a very precise choice: to intentionally leave an unfulfilled space, that means the allowance to leave space to the imagination in order to complete it.

The deliberate and conscious use of the void in Suzhou gardens, legitimate the surrounding presences, allowing each element to possess its own autonomous and independent sphere, thus avoiding the creation of overlapping, giving life, nevertheless, to a peaceful compositional harmony, which conveys a sense of depth. Oriental culture, dedicated to the essential, the silence and the light, invites us to reflect on the distance and relationships that are established between the elements, about their relationship rather than their nature of ornament. Objects and furniture, for example, are placed according to "weak" logic, and yet manage to create a tension and a beauty that "fills the void" enchants and surprises.

"It is a receptacle of halftones and shadows, white spaces that are not to be covered immediately, but enjoyed as they are, an infinite number of arts that aim not at the aesthetic product but at the act of space" (Calza, 1982, p.109). In this context, literally, it is understood as spatium, fracture, pause. As in music, where the pause has the same value as a note, also in architecture, the vacuum should not be a space to be occupied: a space can be empty, but be dense. In summary, Suzhou gardens are a manifesto of the space-time relation in East, that take us to deeply reflections on the necessity of material of memory. They make us at the same time think about a necessary sensitivity capable of recognizing a value evident in the "weak" and intangible, but capable of tracing possible future scenarios. The Suzhou gardens show that emptiness and absence can be expressed spatially. They are an example and partial synthesis of oriental culture, impregnated with a spatial logic to make non-existence visible. In Suzhou, nonexistence is a patrimony of humanity.
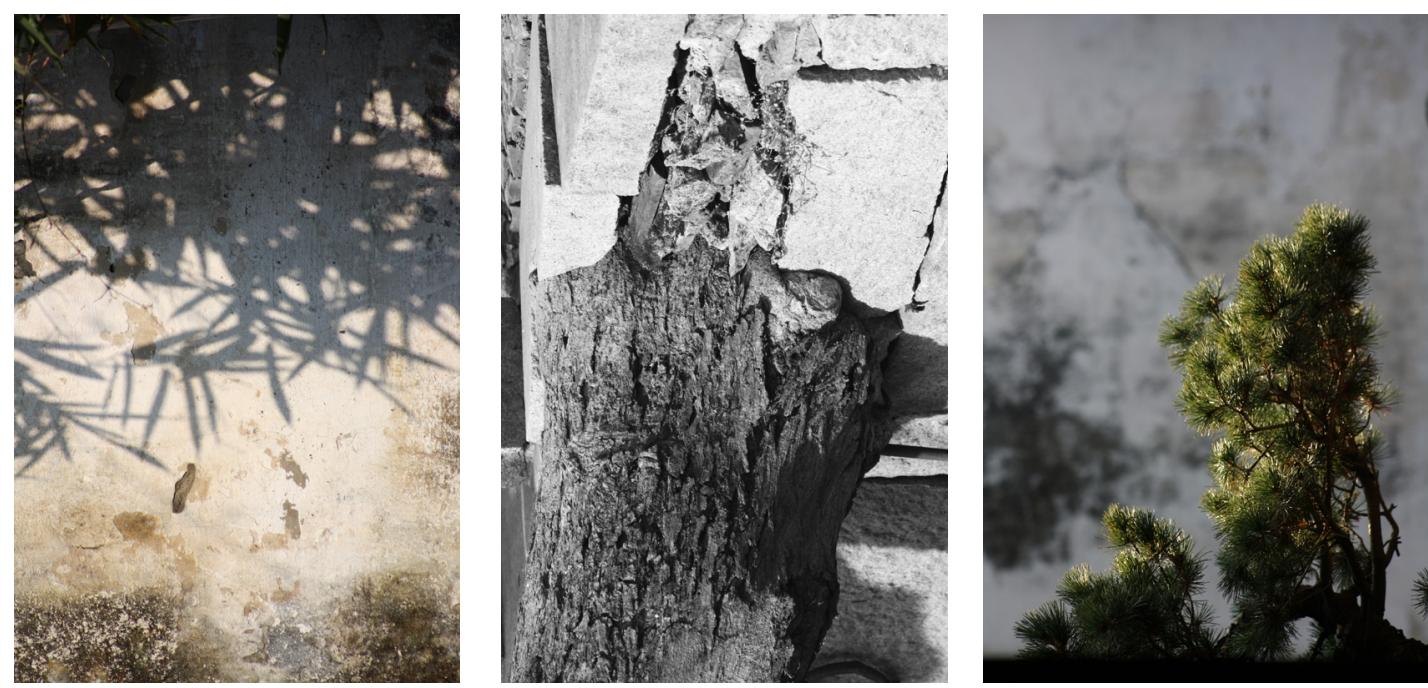

Figure 3. The persistent Suzhou gardens. From left to right: Shadows of bamboo. Nature and artifice, eternal struggle. The void as space, the white wall completing with time. Photos: Juan Carlos Dall'Asta 


\section{The case of Syracuse and the Rocky Necropolis of Pantalica.}

The excavation campaigns, which bring to light archaeological finds, produce feedback on the morphological dynamics in urban spaces: firstly because they reverse the direction of anthropic stratification, secondly because they cause tears, fractures and gaps in the territorial palimpsests (Gritti, 2016).

In this perspective, the UNESCO site that brings together the city of Syracuse and the Rocky Necropolis of Pantalica is a case of extraordinary importance to understand the meaning and implications of the relationship between the historical and archaeological heritage and the suburbs of urban peripheries, where spaces with uncertain destiny live together with natural resources often neglected. The Syracusan UNESCO site system is the largest complex of settlements in the Euro-Mediterranean basin: it includes rock settlements, Greek-Roman colonies, early Christian and medieval settlements, expressions of Arabic, Norman, Aragonese cultures, and finally a formidable synthesis, operated in the Baroque period, on Ortigia Island to remedy the effects of a natural disaster (Cavallari, 2002).

Inserted in natural landscapes of rare beauty, which integrate the system of the Iblei Mountains and the coastline with the most distinctive features of biodiversity across Eastern Sicily, the city of Siracusa and the Rocky Necropolis of Pantalica can be considered morphologically as part of a single territorial system integrated by the presence of the source, the course and the mouth of the Anapo river (Grande, 1996).

The whole Syracusan territory is characterized by a structural relationship between environment, landscape, topography and geomorphology, which sees the undisputed protagonism as the hydrographic grid. Over several millennia of history, human settlements in the Syracuse area have been shaped by research, regulation, and water management to the extent that the main factors of identity and difference in the territorial context depend directly or indirectly on the relationship with water.
The Necropolis of Pantalica (Bernabò, 1990) and the city of Siracusa (Voza, 1999) have been arisen and developed in places where this complex hydrographic basin begins and ends, on the surface of the courses of the Anapo and Ciane rivers and, in the subsoil, from an even larger pattern that descends from Mount Lauro, crosses the gorges of Calcinara and the high Anapo Valley, feeds the Pantano Grande to the gates of the city, reaches the island of Ortigia and flows into the natural coves identified as Porto Grande and Porto Piccolo.

Awork of exceptionalhistoric-archaeological value has sealed this relationship: the Galerni aqueduct. Built from $480 \mathrm{BC}$, perfected in Roman times according to the Vitruvio dictates, maintained in efficiency until the eighteenth century, this formidable example of architecture and hydraulic engineering that captures clean water from the sources of the Anapo river and the Calcinara torrent, to take it to Siracusa, is still partially operating along a route that under full use has reached $40 \mathrm{~km}$. (Sequenzia \& Todini, 2013).

Despite these historical evidence, the declarations that have set up the UNESCO site and the criteria that have enshrined its exceptional nature, are devoid of any reference to the relationship with water and human works that have made it possible to use it4. This negligence, only partly mitigated by the contents of the Management Plan (Syracuse and the Necropolis of Pantalica, Management Plan, 2005) is not negligible and has many implications, even with regard to morphological issues in this contribution.

As in the countryside around Rome, so also in Syracuse it can be seen that some of the main archeological areas, now located in peripheral contexts of the city, share their space with vast portions of the ground, seemingly lacking in quality and structure and mostly excluded from urban and rural use strategies. In these places, the problems arising from mismanagement of environmental resources are almost always evident.

Following the course of the Anapo river in the direction of the mouth, along the boundary defined by the southern remnants of the Dionysus walls, a precious ecosystem is therefore threatened by high dangers, 
which can be detected in close proximity to recent antropic interventions (reclamation, channeling, embankments) conditioned by previous systems of regulation of hydrogeological equilibria on a territorial scale. Thus, exceptional elements of the city's historical and archaeological structure are subject to floods, along with suburbs of the urban periphery, where they have chosen to waterproof the soils, despite the indications of ancient toponomastics being unmistakable in this sense by identifying the cards as well as Pantano Grande, a Pantano Piccolo. Indeed, the picture of the complexities triggered by the wrong choices is at present even worse, due to the downward drainage of debris along the river basins of Anapo and Ciane and the high level of pollution of the waters that reach the sea in the basin of Porto Grande.

In human settlements that boast a millennial history, the features of exceptionality are often related to singular manifestations of degradation and abandonment of settlements, according to historically determined cycles. This condition is repeatedly repeated in the pages of "Territorios", the book in which Ignasi de Solà-Morales spelled out the concept of "terrains vagues" and in which Saskia Sassen introduced the theme of social and cultural relations between the physical dimensions of Inhabited space and their inevitable fate of archaeological finds of the future (Solá Morales \& Sassen, 2002).

Even in the light of these considerations, the most careful and in-depth morphological studies, those who read the city as a dynamic system, have emphasized the relationship between the topography of urban and rural centers, the use of environmental resources and resilience of established communities. The case of the UNESCO sites of Siracusa and Pantalica shows that this attention must be expressed in a historical perspective and must refer to a dimension that can not be ignored by the architectural and urban design without which the list's paradoxes are likely to make only the best intentions for the enhancement of the heritage of mankind only efficient but not effective.

\section{Conclusion. Layers, memory, time and space}

When talking about the three cases it can be appreciated that despite its diametrical difference in many senses, there are interconnected topics: layers, memory, time and space. In the process of reflection in which this three cases are parallel studied, we can find that the built, the demolished and the banal void vs. the charged void are always attempts to invigorate the historical model and its given morphology.

Quito's historical northern limit, Suzhou gardens and Syracuse-Pantalica express examples of physical, temporal and cultural stratigraphy. The three cities show the value of a tangible and invisible memory that is detected in the reading of urban and architectural transformation, sometimes wisely intervened and catalogued, sometimes not. Although the three cases are different, the habitat transformation is a substantial component to understand, in a discontinuous reading process between the layers, the identity path of the project.

The three case studies show the responsibility of the historical urban structure in the formation of the local memory and the social habitat. Rescuing the analysis of the cities, it emerges the need to read the urban morphology of the historical centres as a dynamic system, a meeting place between the population and its physical environment that builds a reciprocal and mutant experience due to its volumetric elements and its empty identities.

In the three cases it has been identified that, as Alison and Peter Smithson said, architecture and urbanism are inseparable, because the buildings encapsulate urban ideas and the urban systems are the means by which buildings function effectively (Smithson, 2005). As a compliment, it is mandatory to be concerned with the life and the dynamics in these places of memory, a life that, even if it is related to people or nature, is constantly changing and renovating its essence through time and space. 

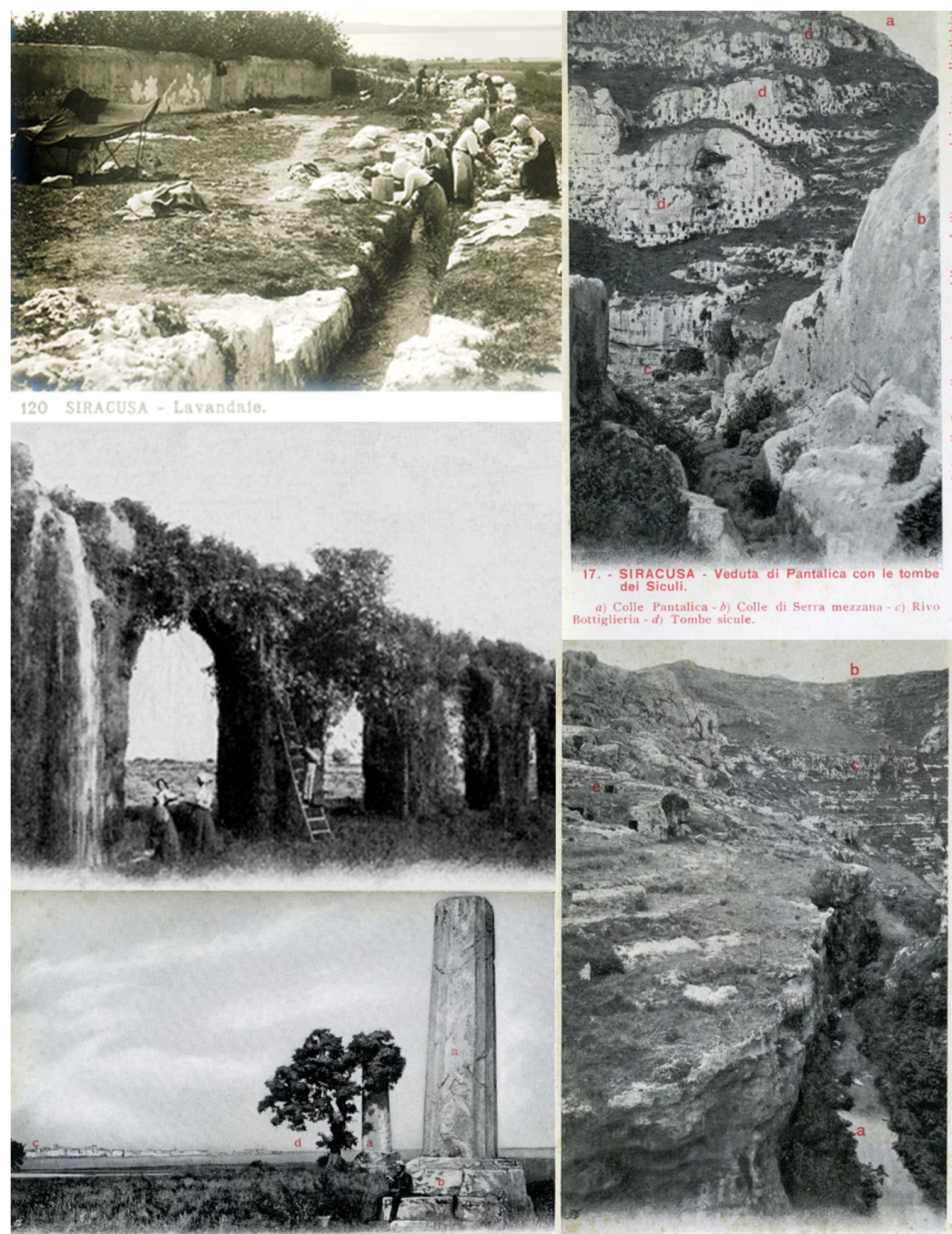

14. SIRACUSA - Veduta delle rovine del Tempio di Giove Olimpico col panorama del gran porto.
16. - SIRACUSA - Veduta delle sorgenti del grande acquedotto Galermi, sotto Pantalica.

a) Rivo Bottiglieria ove ha origine l'acquedotto $-b$ ) Colle di Pantalica Bottiglieria ove ha

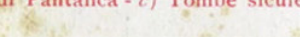

Figure 4. Collage of ancient postcards from Syracuse 


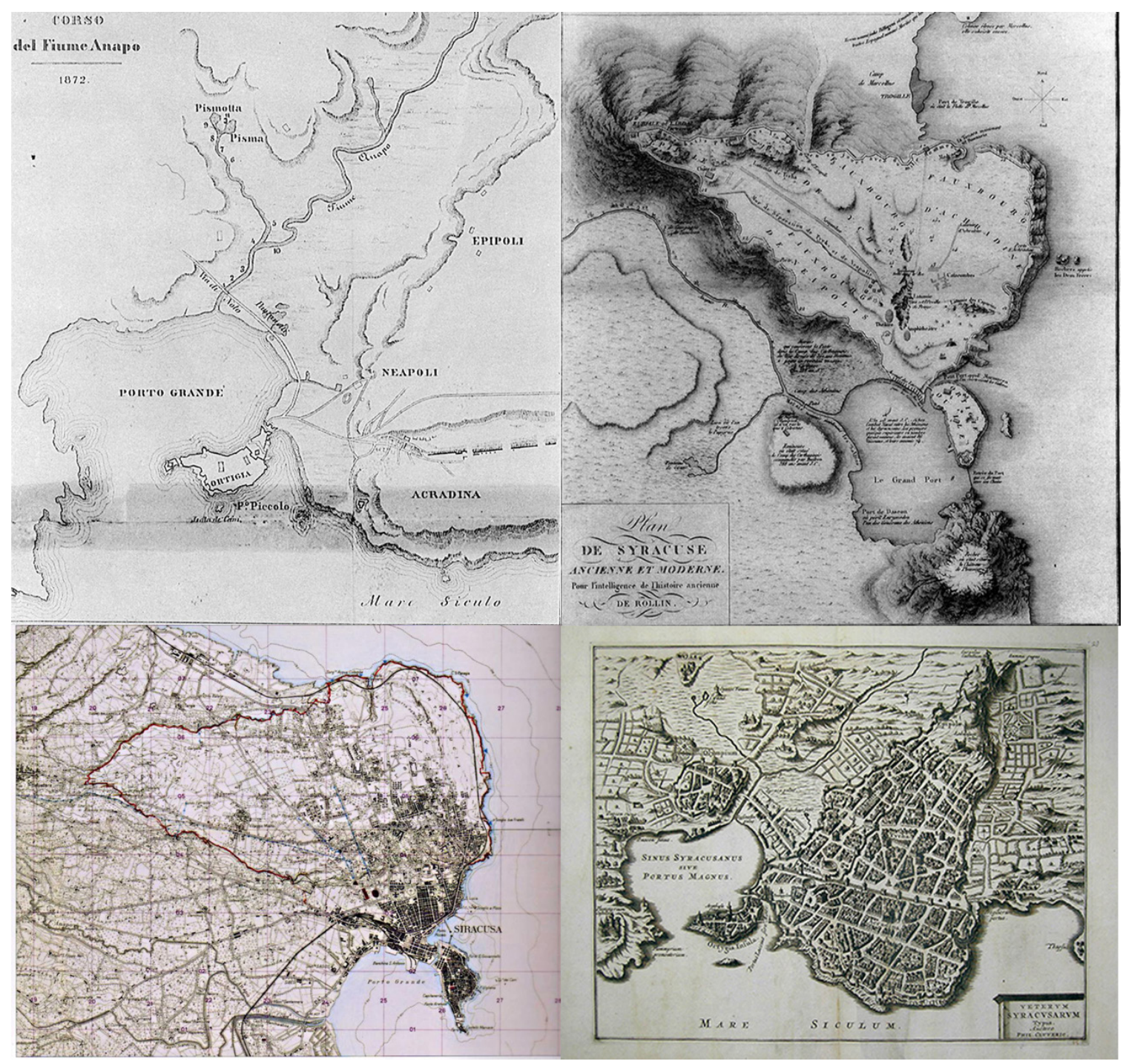

Figure 5. Collage of ancient maps from Syracuse

\section{Notes}

${ }^{1}$ In addition to the considerations for constructing these "places of memory", proposed by Augé, we must take into account what David Lowenthal exposed: 'it is not an inquiry into the past, but a celebration of it ... a profession of faith in a past tailored to presentday purposes'. (Rodney, 2010)

2 http://whc.unesco.org/en/criteria/. “ii) to exhibit an important interchange of human values, over a span of time or within a cultural area of the world, on developments in architecture or technology, monumental arts, town-planning or landscape design". "iv) to be an outstanding example of a type of building, architectural or technological ensemble or landscape which illustrates (a) significant stage(s) in human history"

${ }^{3} \mathrm{http}: / /$ whc.unesco.org/en/list/2.

${ }^{4}$ http : //whc.unesco.org/en/list/1200 


\section{References}

D’Alfonso, E.; ed. (1995). Attualità della forma urbana.

Augé, M. (2009). Non luoghi, Peschiera Borromeo. Milano: Eleuthera.

Augé, M. (1995). Non-Places. Introduction to an Anthropology of Supermodernity. London: Verso.

Bernabò Brea, L. (1990). Pantalica. Ricerche intorno all'anaktoron. Cahiers du Centre Jean Bérard, 14.

Calza, G.C.; Junichiro T., in Junichiro, T. (1982). Libro d'ombra. Milano, Bompiani.

Cavallari, F.S; Holm, A. (2002). Topografia archeologica di Siracusa.

Choay, F. (1992). The allegory heritage. Paris, Seuil.

De Solà-Morales, I., \& Sassen, S. (2002). Territorios. Gustavo Gili.Gehl, J. (2014). Ciudades para la gente. Buenos Aires: Infinito.

Grande, S. (year). Inquadramento geografico dell'area iblea. Bollettino Accademia Gioenia Scienze Naturali, vol. 29 (352): 19 - 26.

Gritti, A. (2016). "Archaeology" in Recycled Theories.

Lynch, K. (1960). La imagen de la ciudad. Barcelona: Gustavo Gili.

Peralta, E., \& Moya, R. (2007). Guía Arquitectónica de Quito. Quito: TRAMA.

Ricci, A. (Ed.). (2002). Archeologia e urbanistica. International School in Archaeology (Certosa di Pontignano 2001) (Vol. 53). All'Insegna del Giglio.

Rodney, H. (2010). What is heritage? Understanding the politics of heritage, 5-42.

Smithson, A.; \& Smithson, P. (2005). The Charged Void-Urbanism. Monacelli Press.

Stravinsky, I. (2003). Poetics of Music in the Form of Six Lessons (Vol. 66). Cambridge, Massachusetts, London: Harvard University Press.

Voza, G. (1999). Nel segno dell'antico: archeologia nel territorio di Siracusa. A. Lombardi. 